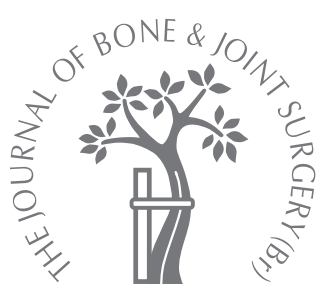

K. A. M. El-Gafary, K. M. Mostafa, W. Y. Al-adly

From Assiut University, Assiut, Egypt
K. A. M. El-Gafary, MD, Professor

K. M. Mostafa, MD, Assistant Professor

W. Y. Al-adly, MD, Lecturer Department of Orthopaedics Assiut University, P O Box 71515, Assiut City, Egypt.

Correspondence should be sent to Dr K. M. Mostafa; e-mail: khaledbalam@yahoo.com

(C)2009 British Editorial Society of Bone and Joint Surgery doi:10.1302/0301-620X.91B10. $22431 \$ 2.00$

$J$ Bone Joint Surg $[\mathrm{Br}]$ 2009;91-B:1322-5.

Received 10 February 2009;

Accepted after revision 15 June 2009

\title{
The management of Charcot joint disease affecting the ankle and foot by arthrodesis controlled by an Ilizarov frame
}

\author{
EARLY RESULTS
}

\begin{abstract}
Charcot osteoarthropathy of the foot is a chronic and progressive disease of bone and joint associated with a risk of amputation. The main problems encountered in this process are osteopenia, fragmentation of the bones of the foot and ankle, joint subluxation or even dislocation, ulceration of the skin and the development of deep sepsis. We report our experience of a series of 20 patients with Charcot osteoarthropathy of the foot and ankle treated with an llizarov external fixator. The mean age of the group was 30 years (21 to 50). Diabetes mellitus was the underlying cause in $\mathbf{1 8}$ patients. Five had chronic ulcers involving the foot and ankle. Each patient had an open lengthening of the tendo Achillis with excision of all necrotic and loose bone from the ankle, subtalar and midtarsal joints when needed. The resulting defect was packed with corticocancellous bone graft harvested from the iliac crest and an llizarov external fixator was applied. Arthrodesis was achieved after a mean of 18 weeks (15 to 20 ), with healing of the skin ulcers. Pin track infection was not uncommon, but no frame had to be removed before the arthrodesis was sound.
\end{abstract}

Every patient was able to resume wearing regular shoes after a mean of 26.5 weeks ( 20 to 45 ).

Charcot osteoarthropathy of the foot and ankle is an aggressive process with destruction of bone and joints and subsequent deformity. Although the pathogenesis of a Charcot foot remains unclear, many theories have been advanced and it seems certain that its origin is multifactorial. ${ }^{1}$ Suggested causes include neurovascular impairment, the presence of a peripheral sensory and motor neuropathy, biomechanical factors and autonomic neuropathy. ${ }^{2}$ The presence of a motor neuropathy may lead to changes in the integrity of the arch of the foot and alter the distribution of pressure in the foot. A concomitant sensory neuropathy may result in sites of increased loading remaining unnoticed, which can induce microfractures and bone deformity. Repeated trauma to an insensitive foot leads to laxity of ligaments and instability of joints with resultant bone damage. ${ }^{3,4}$ Sympathetic denervation will induce active bone resorption and osteopenia by osteoclastic activity. An autonomic neuropathy produces impairment of vascular smooth muscle tone with ensuing vasodilatation in the small arteries and an increase in skeletal blood flow. The resultant demineralisation can predispose to the development of Charcot osteoarthropathy. ${ }^{3,4}$ However, neuropathic osteoarthropathy (acute Charcot foot) is also characterised by uncontrolled inflammation in diabetic patients because of the presence of an abnormal expression of nuclear transcription factor NF-(kappa) B, associated with the increased release of proinflammatory cytokines, such as tumour necrosis factor-alpha and interleukin-1 beta, with an increased osteoclastogenesis which results in bone softening and destruction, and, in turn, potentiates the inflammatory process. ${ }^{5,6}$

Diabetic ulcers occur most commonly in the forefoot under the metatarsal heads or at the interphalangeal joint of the hallux. If an ulcer is associated with clawing of the toes as a result of the intrinsic muscle paralysis found in diabetic, somatic or peripheral neuropathy, successful treatment is difficult. ${ }^{7}$ Wagner $^{8}$ developed a classification for diabetic plantar ulcers and a matching treatment algorithm as follows: grade 0 , skin intact but bony deformities producing a 'foot at risk'; grade 1, localised superficial ulcer; grade 2, deep ulcer to tendon, bone, ligament or joint; grade 3, deep abscess, osteomyelitis; grade 4 , gangrene of toes or forefoot; and grade 5, gangrene of the entire foot.

Eichenholtz ${ }^{9}$ has classified Charcot arthropathy into three stages. In stage I a marked inflammatory process is present with periarticular fractures and joint subluxation which occurs at the end of this stage. During stage II the inflammatory process lessens with an 
Table I. Clinical details of the 20 patients with Charcot osteoarthropathy

\begin{tabular}{|c|c|c|c|c|c|c|c|c|}
\hline Case & Gender & $\begin{array}{l}\text { Age } \\
\text { (yrs) }\end{array}$ & Side & Aetiology & Ulcer & Affected joints & $\begin{array}{l}\text { Previous } \\
\text { long cast }\end{array}$ & Deformity \\
\hline 1 & $\mathrm{~F}$ & 22 & $\mathrm{R}$ & $\mathrm{DM}^{*} \mathrm{I}$ & None & Ankle, subtalar, midtarsal & Yes & Equinovarus ankle and varus forefoot \\
\hline 2 & M & 30 & $\mathrm{~L}$ & DM I & None & Ankle, midtarsal & Yes & Equinovarus ankle and varus forefoot \\
\hline 3 & $\mathrm{M}$ & 40 & $\mathrm{R}$ & DM II & $\mathrm{G} 1^{\dagger}$ & Ankle & No & Equinovarus ankle \\
\hline 4 & $\mathrm{~F}$ & 50 & $\mathrm{~L}$ & DM II & G 1 & Ankle & No & Equinovarus ankle \\
\hline 5 & $\mathrm{~F}$ & 21 & $\mathrm{~L}$ & DM I & - & Ankle, midtarsal, tarsometatarsal & Yes & Equinovarus ankle and varus forefoot \\
\hline 6 & M & 26 & $\mathrm{R}$ & DM II & None & Ankle, subtalar & Yes & None \\
\hline 7 & M & 32 & $\mathrm{~L}$ & DM II & None & Ankle & No & None \\
\hline 8 & M & 45 & $\mathrm{~L}$ & Leprosy & G 2 & Ankle, subtalar & No & Equinovarus ankle \\
\hline 9 & $\mathrm{~F}$ & 22 & $\mathrm{R}$ & DM I & None & Ankle, subtalar, midtarsal & No & Equinovarus ankle \\
\hline 10 & M & 30 & $\mathrm{~L}$ & DM II & None & Ankle & No & None \\
\hline 11 & M & 29 & $\mathrm{R}$ & DM I & None & Ankle & Yes & None \\
\hline 12 & $\mathrm{~F}$ & 21 & $\mathrm{~L}$ & DM I & G 2 & Ankle, subtalar & Yes & Equinovarus ankle \\
\hline 13 & M & 40 & $\mathrm{R}$ & DM II & None & Ankle, midtarsal, tarsometatarsal & No & Equinovarus ankle and varus forefoot \\
\hline 14 & $\mathrm{~F}$ & 33 & $\mathrm{R}$ & DM II & None & Ankle & No & Equinovalgus ankle \\
\hline 16 & $\mathrm{~F}$ & 22 & $\mathrm{~L}$ & DM II & None & Ankle & Yes & None \\
\hline 17 & $\mathrm{~F}$ & 30 & $\mathrm{R}$ & Not known & None & Ankle, subtalar & Yes & None \\
\hline 18 & M & 30 & $\mathrm{R}$ & DM II & G 2 & Ankle, subtalar, midtarsal & No & Equinovarus ankle \\
\hline 19 & $\mathrm{~F}$ & 23 & $\mathrm{R}$ & DM II & None & Ankle, subtalar, midtarsal & No & Equinovarus ankle \\
\hline 20 & $\mathrm{M}$ & 22 & $\mathrm{R}$ & DM I & None & Ankle, midtarsal, tarsometatarsal & Yes & Equinovarus ankle and varus forefoot \\
\hline
\end{tabular}

evident radiological deformity. In stage III (the healing stage), the foot and ankle are swollen, deformed and painless. Shibata, Tada and Hashizume ${ }^{10}$ added a stage 0 acute phase in which there was absence of any radiological evidence of a Charcot foot.

Conservative or operative treatment can be used depending on the situation at the time of presentation. After early recognition and diagnosis in the acute stage, a Charcot foot and ankle can be managed by immobilisation in a total contact cast for a prolonged period to protect the soft tissues by reducing the load on the ulcer and supporting the foot and ankle. ${ }^{11}$ However, this may result in an extended time in a cast with resolved cases showing gross deformity and risk of further ulceration.

Surgery may be undertaken in patients with Chacot joint disease of the foot and ankle to debride necrotic tissue, or to restore the alignment and stability of the foot and ankle. Procedures may include lengthening of the tendo Achillis, hindfoot osteotomy and arthrodesis using internal or external fixation.

We present the results of using Ilizarov external fixation to treat Charcot arthropathy of the foot and ankle.

\section{Patients and Methods}

Between 2004 and 2007, we treated 20 patients with stage-II Charcot arthropathy of the foot and ankle. There were 11 men and nine women with a mean age of 30 years (21 to 50 ). The right side was involved in 12. Diabetes mellitus was the major underlying cause: eight patients had type-I diabetes mellitus and ten type-II. One patient had leprosy and in one there was no apparent cause. All the patients presented with a deformed swollen warm erythematous foot and ankle. A total of ten patients had previously been treated by the application of a long-leg cast for more than 12 weeks without any improvement in their ability to walk. There were five patients with chronically infected ulcers on the foot and ankle: two had grade-I ulcers on the plantar aspect of the foot and three grade-2 ulcers on the lateral side of ankle due to varus deformity and subluxation (Table I). No patient had a history of major trauma to the foot and ankle. Radiographs of the foot and ankle showed bone resorption, intra-articular fractures, osteochondral fragmentation and formation of periarticular debris. Subluxation and joint deformities were present in 14 patients of whom 13 had an equinovarus deformity of the ankle: six had an associated adduction or varus deformity of the foot at the level of the forefoot. One patient had an equinovalgus deformity at the ankle without deformity of the foot.

In addition to clinical and radiological evaluation, Doppler ultrasonography was used to assess the vascularity of the foot.

Operative technique. All operations were carried out under general or spinal anaesthesia with a pneumatic tourniquet. Pre-operative prophylactic broad-spectrum antibiotics were given. Cephalosporin was usually started within one hour before surgery at a dose of $1 \mathrm{gm}$ and continued for another three days twice daily. Oral quinolone antibiotic tablets $(500 \mathrm{mg})$ were then taken for ten days twice daily. The leg and foot were prepared and draped in the usual manner and the iliac crest prepared as a donor site for the bone graft. The tendo Achillis was lengthened through a 


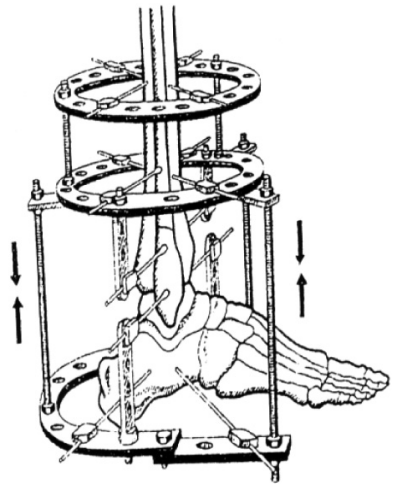

Fig. 1a

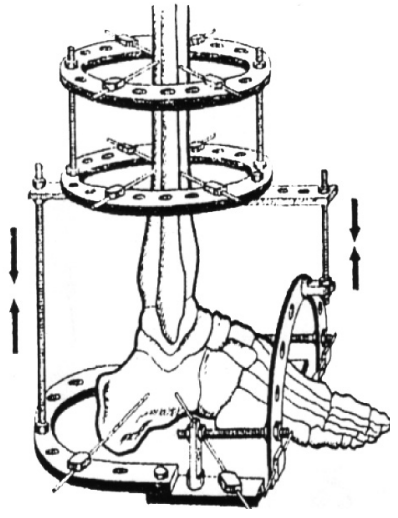

Fig. 1b
Diagram of the construction of the llizarov fixator showing a) the frame assembly for arthrodesis of the ankle and subtalar joints and b) extension of the frame for the management of deformity of the forefoot.

posteriorly-based incision in patients with a fixed deformity. An anterolateral approach was used for access to the ankle and most of the tarsal bones.

The ankle was extensively debrided in all patients with removal of the remaining articular cartilage and excision of any loose bone fragments or avascular bone until healthy bleeding bone was exposed. At the same time, any disrupted or possibly infected soft tissue was removed, which left a large cavity. The talus was visualised and again any avascular bone was debrided. The resulting defect in the ankle and subtalar joints was packed with corticocancellous bone graft harvested from the iliac crest. Exposure of the midtarsal and Lisfranc joints was needed in nine patients. This was achieved by extending the anterolateral approach to the dorsum of the foot. Further debridement of these joints was undertaken and more corticocancellous bone graft was packed into the defect. Temporary stabilisation of the foot and ankle was performed under fluoroscopic control using a Steinmann pin inserted from the heel to tibia with the ankle and hindfoot in a neutral position for one month. An Ilizarov frame spanning the tibia, ankle and foot was used to maintain position while the arthrodesis of the hindfoot developed. Extension of the ankle frame to the forefoot was required in nine patients.

The Ilizarov external fixator consisted of two tibial rings linked by three rods. Tensioned wires (two per ring) and two anterior Schanz pins secured the frame to the tibia. The construct for the foot consisted of a calcaneal half or $5 / 8$ ring connected to the hindfoot by tensioned wires and to the tibial frame by three threaded rods. The frame was extended to the forefoot in nine patients by the addition of another half ring which was connected to the main frame and secured to the metatarsals with tensioned wires (Fig. 1). Immediate calcaneotibial compression was applied before the wound was closed in layers.
During the first three post-operative days, the foot and ankle were observed for swelling, vascularity and temperature. Gradual compression between the tibia and foot frames was applied at rate of $1 \mathrm{~mm} /$ day until complete compression was achieved between the arthrodesed surfaces. Restricted weight-bearing was allowed for a mean of ten weeks, after which unrestricted weight-bearing was undertaken.

The patients were reviewed weekly for the first two weeks, then every two weeks for the following months until the removal of the Ilizarov frame after which a below-knee plaster cast was applied.

\section{Results}

The mean follow-up was for 20 months (12 to 30) and no patient was lost to follow-up. Early superficial infection was encountered in two patients who were managed successfully by the administration of parenteral antibiotics. No early or late vascular complications ensued. Pin track infection occurred in 15 patients and was managed by treatment with local topical antibiotics and pin-site care. Persistent oedema and pain occurred in two patients. Skin ulceration healed completely within four to six weeks. No post-operative recurrence of ulceration was recorded. Arthrodesis occurred at a mean of 18 weeks ( 15 to 20 ) with a dynamisation period of a mean 3.5 weeks ( 3 to 4 ) (Fig. 2). The mean post-operative period in a below-knee plaster cast was five weeks (4 to 6). The mean total treatment period was 26.5 weeks (20 to 29). The mean period of restricted weight-bearing was ten weeks (6 to 15) with a mean duration of unrestricted weight-bearing of 18 weeks (12 to 31 ). The mean time for patients to return to wearing regular shoes was 26.5 weeks (20 to 45). Shortening of the leg below the knee occurred in six patients with a mean reduction of $2 \mathrm{~cm}$ (1.5 to 2.5), while the remaining 14 patients had no leg-length discrepancy. Solid union and correction of deformity were achieved in all patients.

\section{Discussion}

A major problem in patients with chronic diabetes mellitus is the development of peripheral neuropathy. Sensory loss leads to neuropathic ulceration which is aggravated in the presence of foot and ankle deformity and causes excessive pressure on deformed areas. ${ }^{12,13}$ The major aim in treating Charcot arthropathy of the foot and ankle is to correct the deformity so that that there is appropriate distribution of pressure for healing and prevention of skin ulceration. ${ }^{14}$ Conservative treatment using a total contact cast may result in a poor outcome because of inadequate fixation, a high rate of infection, a compromised blood supply and nonunion. ${ }^{14}$ Open correction with internal fixation for Charcot osteoarthropathy is associated with a high rate of complications and failure because of infection, bone softening, resorption, fragmentation and breakage of the implant. ${ }^{11}$

The main advantages of using an Ilizarov external fixator in the treatment of Charcot osteoarthropathy are the ability to gradually correct deformity in the post-operative 


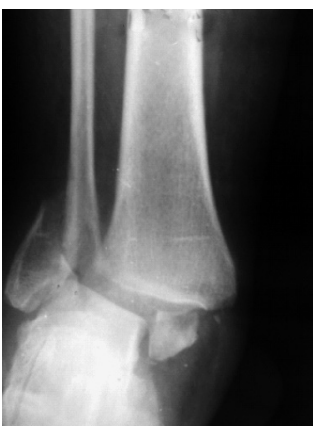

Fig. 2a

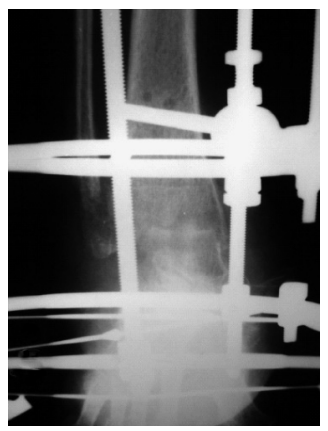

Fig. $2 b$

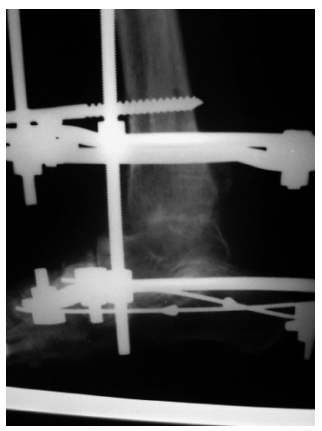

Fig. 2c

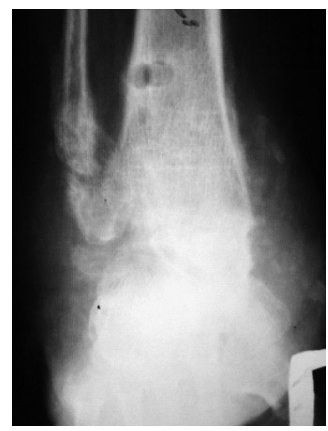

Fig. 2d

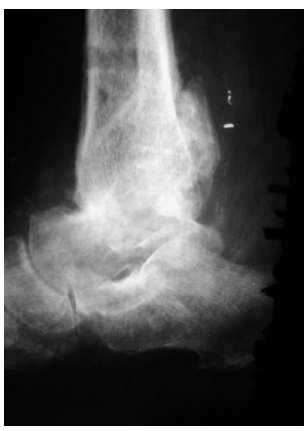

Fig. 2e

Radiographs of a 50-year-old man with a Charcot ankle showing a) pre-operative anteroposterior view of the ankle with lateral subluxation and destruction of the malleoli, b) and c) post-operative views with the llizarov frame in place and d) and e) complete consolidation and removal of the frame after 25 weeks.

period and maintain this stable correction while weightbearing $^{11}$ even in the presence of soft bone.

In our study, 20 patients with a stage-II Charcot osteoarthropathy underwent arthrodesis of the foot and ankle with an Ilizarov external fixator and obtained anatomical reduction and stable fixation without major complications. Wang, Le and Tsukuda ${ }^{15}$ had comparable results within 3.1 months and Cooper ${ }^{16}$ reported successful arthrodesis within 4.2 months. Farber et $\mathrm{al}^{17}$ had a mean time to fusion of nine weeks in their series followed by the application of a total contact cast for a mean of 19 weeks without subsequent ulceration. In a series reported by Simon et al, ${ }^{14}$ patients were able to resume wearing regular shoes within 27 weeks.

Correction and stabilisation of foot and ankle deformities with an Ilizarov external fixator are effective and allow correction of the deformities, while avoiding the complications of internal fixation. It also enables early weight-bearing, care of soft tissues, prevention of skin ulceration and avoidance of amputation. However, it is recognised that Ilizarov external fixation is not without some disadvantages since it involves a lengthy duration of treatment, is commonly associated with pin-track infection and requires surgical expertise and dedicated instrumentation. Nevertheless, these problems are outweighed by the advantages of the technique.

No benefits in any form have been received or will be received from a commercial party related directly or indirectly to the subject of this article.

\section{References}

1. Young MJ, Marshall AB, Adams JE, Boulton AJM. Osteopenia, neurological dysfunction and the development of Charcot neuroarthropathy. Diabetes Care 1995;18:34-8.

2. Sanders LJ. The Charcot foot: historical perspective 1827-2003. Diabetes Metab Res Rev 2004;20(Suppl):4-8.

3. Armstrong DG, Todd WF, Lavery LA, Harkless LB, Bushman TR. The natural history of acute Charcot's arthropathy in a diabetic foot specialty clinic. Diabet Med 1997; 14:357-63.

4. Jeffcoate WJ. Abnormalities of vasomotor regulation in the pathogenesis of the acute charcot foot of diabetes mellitus. Int J Lower Extrem Wounds 2005:4:133-7.

5. Jeffcoate WJ, Game F, Cavanagh PR. The role of proinflammatory cytokines in the cause of neuropathic osteoarthropathy in diabetes. Lancet 2005;10:2058-61.

6. Jeffcoate WJ. Theories concerning the pathogenesis of the acute Charcot foot suggest future therapy. Curr Diab Rep 2005;5:430-5.

7. Richardson EG. Diabetic foot. In: Canale ST, ed. Campbell's operative orthopaedics. Ninth ed. London: Mosby, 1998.

8. Wagner FW. The diabetic foot. Orthopedics 1987;10:163.

9. Eichenholtz SN. Charcot joints. Springfield, IL: Charles C Thomas, 1966.

10. Shibata T, Tada K, Hashizume C. The results of arthrodesis of the ankle for leprotic neuroarthropathy. J Bone Joint Surg [Am] 1990;72-A:749-56.

11. Bradley L, Lamm, Paley D. Charcot neuroarthropathy of the foot and ankle in limb lengthening and reconstruction surgery. In: Rozbruch SR, llizarov S, eds. Limb lengthening and reconstruction surgery. Vol. 1. London: Informa Healthcare, 2007:221-32.

12. Armstrong DG, Lavery LA, Harkless LB. Who is at risk for diabetic foot ulceration? Clin Podiat Med Surg 1998;15:11-19.

13. Armstrong DG, Lavery LA. Elevated peak plantar pressures in patients who have Charcot arthropathy. J Bone Joint Surg [Am] 1998;80-A:365-9.

14. Simon SR, Tejwani SG, Wilson DL, Santner TJ, Denniston NL. Arthrodesis as an early alternative to non-operative management of Charcot arthropathy of the diabetic foot. J Bone Joint Surg [Am] 2000;82-A:939-50.

15. Wang JC, Le AW, Tsukuda RK. A new technique for Charcot's foot reconstruction. J Am Podiatr Med Assoc 2002;92:429-36.

16. Cooper PS. Application of external fixator for management of Charcot deformities of the foot and ankle. Foot Ankle Clin 2002;7:207-54.

17. Farber DC, Juliano PJ, Cavanagh PR, Ulbrecht J, Caputo G. Single stage correction with external fixation of the ulcerated foot in indivuduals with Charcot neuroarthropathy. Foot Ankle Int 2002;23:130-4 